\title{
EL NOBLE CHECO HEŘMAN JAKUB ČERNÍN DE CHUDENICE Y SU ENCUENTRO CON EL ARTE EN ESPAÑA 1681/1682*
}

\author{
POR \\ Milena HajnÁ \\ Instituto de Historia de CCHS, CSIC/Universidad de Bohemia del Sur, České Budějovice
}

\begin{abstract}
El noble checo Heřman Jakub Černín de Chudenice (1659-1710), primogénito del conde Humprecht Jan Černín de Chudenice (1628-1682), fue un importante diplomático y político en la Corte del emperador Leopoldo I. Su recorrido por España (1681-1682) formaba parte de su viaje de estudios por Europa que hizo durante los años 1679-1682. En una instrucción escrita antes de empezar este viaje, el padre Černín ordenó a su hijo que escribiera un diario en el idioma de cada país por el que estuviera viajando. Gracias al cumplimiento de este deseo de su padre, el joven aristócrata se convirtió en el autor de un diario especial, que, no sólo marca casi todo su camino europeo, sino que también sirve como un interesante documento lingüístico. El conde Černín dedicó el espacio más amplio de su diario a la descripción de los encuentros con las personas importantes, de las fiestas y de los monumentos históricos. Le llamaban la atención ante todo las obras arquitectónicas o de arte, cuya importancia ya estaba públicamente confirmada y que conocía por medio del padre, el preceptor, sus guías ocasionales o los libros de viajes. Todo el viaje español está marcado por el interés especial de Černín por la arquitectura. Aunque sabía bién apreciar la calidad de pinturas y de esculturas, las obras concretas y los nombres de sus autores, los apuntó en el diario sólo esporádicamente. Se nota, que los conocimientos de Černín no carecen de cierta erudición, pero no es posible ver en este joven a un experto en arte.
\end{abstract}

Palabras claves: Heřman Jakub Černín de Chudenice; Viajeros; España, Siglo XVII; Arquitectura.

The Czech noble Heřman Jakub Černín of Chudenice (1659-1710) was the eldest son of Count Humprecht Jan Černín de Chudenice (1628-1682), an important diplomat and politician at the Court of Emperor Leopold I. His journey throughout Spain (1681-1682) formed part of his European "grand tour" (1679-1682). Before setting off on this trip, Count Humprecht instructed his son to write a diary in the languages of the lands he visited. Thanks to satisfying his father's wishes, Heřman Jakub became the au-

* La realización de este trabajo ha sido posible gracias a la Agencia Española de Cooperación Internacional del Ministerio de Asuntos Exteriores y de Cooperación, por conceder la beca de investigación en el Consejo Superior de Investigaciones Científicas, con la que era posible concluir los estudios de este tema. 
thor of an exceptional diary, which not only records his entire European itinerary, but is also an interesting linguistic document. The young Černín dedicated most of the space in his diary to describing his meetings with important figures, festivities and historical monuments. Although some erudition can be observed in his knowledge of art, he cannot be considered a specialist or an art expert. What most attracted his attention were works of art and architecture whose significance was already well known, and which he had heard about through his father, his tutor or occasionally through local guides and travel books. The whole of Černín's Spanish journey was marked by his special interest in architecture. While he was able to recognise the value and quality of paintings and sculptures, he noted specific works and names of artists only sporadically in his diary.

Key words: Heřman Jakub Černín de Chudenice; Tour of Spain; 17th century; Architecture.

La segunda mitad del siglo XVII, fue una época, en la que la calidad de la persona noble y culta se medía no sólo por sus amplios conocimientos cortesanos, diplomáticos y culturales, sino también por su capacidad de apreciar los objetos bellos y rodearse de ellos en un ambiente armonioso. El saber evaluar las obras arquitectónicas, elegir pinturas, esculturas, muebles, libros, objetos preciosos, escoger tejidos, tapices, prendas de vestir o joyas adecuadas, era no sólo un indicador de lujo o de riqueza, sino también señal de una educación preeminente, del buen gusto y de la elegancia ${ }^{1}$.

El ambiente de la residencia familiar y el ejemplo de sus componentes influían mucho en la primera educación de los jóvenes para dominar estas artes. La familia del noble checo Heřman Jakub Černín de Chudenice (1659-1710, fig. 1)², fue un buen ejemplo de cómo preparar los hijos para la vida en la Corte y atraer su interés por el arte y la ciencia. Heřman Jakub, nació como hijo mayor del conde Humprecht Jan Černín de Chudenice (1628-1682, fig. 2) ${ }^{3}$, importante diplomático y político en la Corte del emperador Leopoldo I. Černín padre fue aficionado a la arquitectura y a la pintura, tenía excelentes conocimientos del teatro y de la música. Durante los años que pasó como embajador imperial en Venecia (1661-1663), no sólo se dedicó a resolver las cuestiones diplomáticas, sino que también daba noticias al emperador sobre las nuevas tendencias en la escenografía del teatro, le enviaba partituras de óperas y negociaba para él las obras de arte de los principales artistas italianos ${ }^{4}$. Asimismo aprovechó su estancia en Italia para ampliar las colecciones artísticas de su familia y así creó una de las galerías de pintura más importantes en la Europa Central. Más tarde mandó construir su palacio cerca del Castillo Real de Praga, que se convirtió en una de las joyas arquitectónicas más apreciadas del barroco europeo ${ }^{5}$. La madre de

${ }^{1}$ La bibliografía sobre este tema está resumida en Adel im Wandel. Politik - Kultur - Konfession 1500 - 1700. Katalog des Niederöesterreichschen Landesmuseums, Viena, 1990; BŮŽEK, V.-KráL, P. (eds.), Aristokratické rezidence a dvory v raném novověku, Opera historica 7, České Budějovice, 1999; KALista, Z., Století andélì a d'ábli̊. Jihočeský barok, Jinočany, 1994; Bonet Correa, A., Fiesta, poder y arquitectura. Aproximaciones al barroco español, Madrid, 1990; J. Brown-J. H. Elliot, Un palacio para el rey. El Buen Retiro y la corte de Felipe IV, Madrid, 1981; M. T. Fernández Talaya, El Real Sitio de La Florida y La Moncloa. Evolución histórica y artística de un lugar madrileño, Madrid, 1999.

${ }^{2}$ El autor del retrato de Heřman Jakub Černín de Chudenice es desconocido.

${ }^{3}$ Karel Škréta y Johannes Borcking son los autores del grabado de Humpracht Jan Černín de Chudenice que se encuentra en Galeria Nacional de Praga. Véase SLAvǐ̌̌̌E, L., "Černínové jako sběratelé a podporovatelé umění", en: L. SlavíčEK (ed.), Artis pictoriae Amatores. Evropa v zrcadle pražského barokního sběratelství, Praga, 1993, pp. 131-169.

${ }^{4}$ Kalista, Z. (edición), Korespondence cisaře Leopolda I. s Humprechtem Janem Černínem z Chudenice, Tomo I, Praga, 1936; SLAVÍČEK, L., op. cit., pp. 131-169.

5 Černín padre, Humprecht Jan Černín de Chudenice, perteneció a una aristocrática familia checa muy antigua e importante, pero a una de sus líneas más pobres. Su padre murió pronto y la madre Zuzana Černínová de Chudenice tuvo que encargarse en la administración de los bienes y en la educación de cuatro hijos menores de edad. Orgullosa 


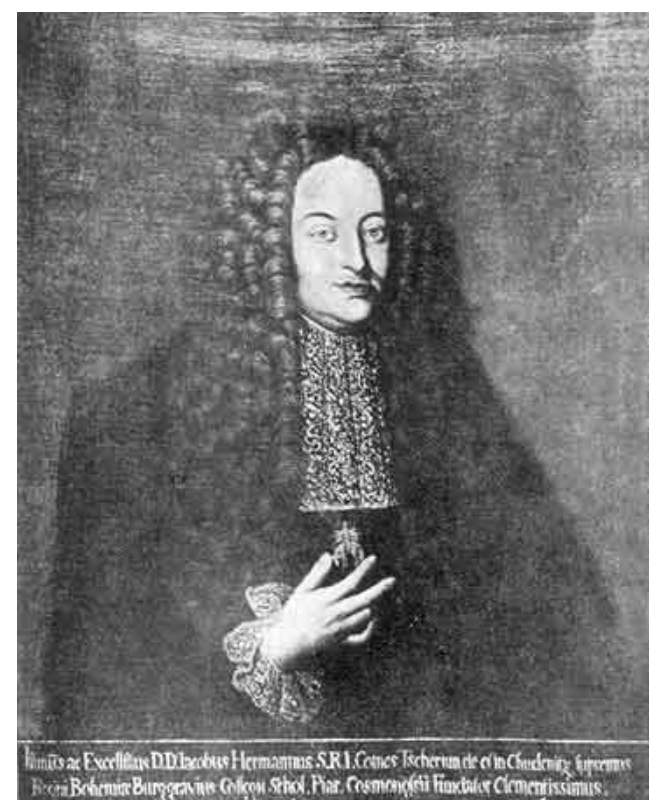

Fig. 1. Autor desconocido, Retrato del Heřman Jakub Černín de Chudenice.

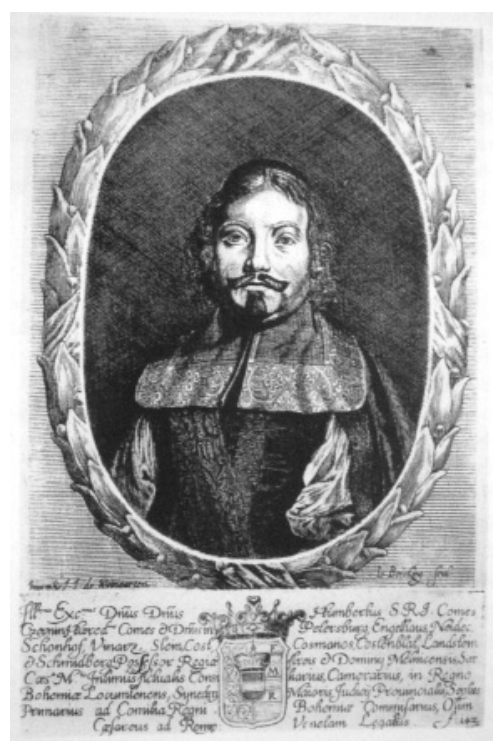

Fig. 2. Karel Škréta y Johannes Borcking, Humpracht Jan Černín de Chudenice, Grabado, Praga, Galería Nacional.

Hěman Jakub Černín fue una aristócrata italiana, Maria Hippolita di Gassoldo, a quien el padre conoció en la Corte del emperador Fernando II ${ }^{6}$.

Los estudios de Černín hijo, igual que otros aristócratas, se referían al dominio de las lenguas y de los comportamientos cortesanos - como bailar, tocar un instrumento de música, montar a caballo o hacer esgrima- y a la educación fundamental en geografía, historia, geometría, arquitectura y arte. Para concluir los estudios Heřman Jakub Černín viajó por Europa entre los años 1678-1682, con la finalidad de afianzar mediante la práctica los conocimientos conseguidos durante sus estudios, presentarse en el escenario de la diplomacia europea, obtener contactos importantes y ampliar los conocimientos imprescindibles para una futura carrera política con éxito en la Corte Imperial ${ }^{7}$. La idea de organizar los viajes de estudios para los caballeros jóvenes, que

a su origen checo mantuvo toda su vida una extensa correspondencia en checo con sus hijos y con los parientes, en la que describía detalladamente la vida cotidiana de su familia -bodas, entierros, bautismos, enfermedades, visitas, viajes-, construyendo así una interesante crónica familiar. Al morir Humprecht Černín de Chudenice en 1645 (un famoso diplomático enviado tres veces por el Emperador a hacer tratos de paz con los otomanos en Turquía) sin hijos, Humprecht Jan heredó los bienes del tío junto con el acceso a los cargos importantes en la Corte Imperial. KaLISTA, Z. (edición), Korespondence Zuzany Černínové z Harasova s jejím synem Humprechtem Janem Černínem z Chudenic, Praga, 1941; Kalista, Z. (edición), op. cit., 1936; Kalista, Z., Mládí Humprechta Jana Černína z Chudenic. Zrození barokního kavalíra, Tomo I-II, Praga, 1932; Ottưv slovník naučný, Tomo VI, 1893, pp. 623-627.

${ }^{6}$ Státní oblastní archiv Treboň (Archivo Regional de Estado, Třeboň, República Checa, a partir de ahora SOA), filial Jinđ̛richův Hradec, Familia Černín, cartón 245.

${ }^{7}$ Las informaciones detalladas sobre este camino son conocidas por el diario de Heřman Jakub Černín que incluye la parte mayor de su itinerario, y por la correspondencia del padre al hijo y a su mayordomo durante este camino. El diario de Heřman Jakub Černín llamó la atención de varios historiadores en el pasado, pero nunca había investigado en su complejidad ni en las consecuencias históricas y artísticas de la época, ante todo por las barreras lingüísticas, pues está escrito en cinco lenguas. En la actualidad se prepara la edición completa del diario por el grupo de investigación 
empezó estar de moda a partir del siglo XVI, se llevó a cabo mediante de una educación abierta y amplia, como la expuesta por el humanista y filósofo Erasmo de Rotterdam (1469?-1536). Según su doctrina, el conocimiento de las culturas diversas y de los diferentes regímenes políticos hacía conocer al viajero la abundancia y la diversidad del mundo y de la vida, de la gente, de las costumbres y del paisaje, lo que legitimaba los viajes educativos. El itinerario elegido tenía una influencia enorme en la futura formación personal, religiosa y cultural de los nobles y de sus cortes, en su afán por construir nuevas obras arquitectónicas, por elegir los objetos del arte y en el mecenazgo de los artistas. Los jóvenes viajeros, aun ignorándolo, formaban parte de la red por la que se ampliaban las informaciones e innovaciones culturales y artísticas en Europa ${ }^{8}$.

El buen estado de la economía de la familia Černín, junto con la generosidad del padre, que le ilusionaba enormemente el viaje de su hijo primogénito, permitió al joven Černín pasar en el extranjero casi cuatro años entre 1678-1682, durante los cuales visitó no sólo Alemania, Austria e Italia (los países más comunes para los viajeros centroeuropeos), sino que pudo ampliar su viaje a Francia, España y Países Bajos. Además, gracias a sus relaciones diplomáticas el padre pudo facilitar a su hijo los encuentros con los personajes más importantes en casi todas las cortes europeas, suministrándole varias cartas de recomendación 9 . Por ejemplo, así comentó Černín padre su relación con el marqués de los Balbases: "Te recomiendo visitar también al embajador de Venecia; al Duca del Sesto, marqués de los Balbases ${ }^{10}$ que estaba presente como embajador de España en la Corte Imperial cuando recibi la orden de Toisón de Oro; así como el marqués

Alexandra Tesaříková, Eva Chodějovská, Milena Hajná y Jana Marešová) liderado por el profesor Zdeněk Hojda de la Universidad Carolina de Praga. La autora de este artículo ha preparado la parte española de la edición. Véase también BINKOVÁ, S., "Španělsko pohledem českých cestovatelů 17. stoletî", en BARTEČEK, I.-RESKO, J. (eds.), České země a Španělsko, Z déjin česko-španělských vztahů, Ostrava, 1996; BINKOVÁ, S.-PolIŠEnSKÝ, J., "Dos testimonios sobre España del siglo XVII", Ibero-America Pragensia, 23, 1989, pp. 131-152; BInKovÁ, S.-PolisenskÝ, J. (edición), Česká touha cestovatelská, deníky a listy ze 17. století, Praha, 1989; BinkovÁ, S., "Madrid y su imagen cambiante según los diarios de viaje de la nobleza de los países checos (siglos XV-XVII)", en Hispanismo en la República Checa, Tomo IV, Praga, 2002; BinkovÁ, S., "Os Países Checos e a Zona Lusitana. (Condactos e testemunhos séculos XV-XVIII.)", in: Ibero-Americana Pregensia, 21, 1987 [impreso 1990], 137-160. HaJNÁ, M., "Retrato del español visto con ojos de los centroeuropeos de los siglos XVI y XVII (La literatura de viajes como fuente para el estudio de la vida cotidiana de la temprana edad moderna)", en ZBUdilovÁ, H. (ed.), La literatura española de los siglos XVI-XVIII en las bibliotecas de Chequia, Moravia y Eslovaquia, Opera romanica 3, České Budějovice, 2002, pp. 84-98; CATAlano, A. (edición), "Heřman Jakub Černín: Deník z cest po Itálii", en Souvislosti, No. 3-4, 2002, pp. 113-123; BílKovÁ, E.-HusÁKovÁ, J.-TesaříkovÁ, A., "Kavalíská cesta Heřmana Jakuba Černína z Chudenic”, en KuBEš, J. (ed.), Historie 2003. Sborník prispěvki̊ ze studentské védecké konference, Pardubice, 2004, pp. 89-118.

${ }_{8}$ El viaje de educación de los jóvenes nobles fue llamado "Grand Tour" por primera vez en el año 1605 en Inglaterra y desde allí este nombre cundió por toda Europa junto con las ideas educativas de Erasmo de Rotterdam. Véase Von Ertzdorff, X.-Neukirch, D. (eds.), Reisen und Reisekultur in Mittelalter und in der Frühen Neuzeit (Vorträge eines interdisziplinären Symposium von 3. - 8. Juni 1991), Amsterdam-Atlanta, 1992; BoBKovÁ, L.-NeudERTOVÁ, M. (eds.), Cesty a cestování v životé společnosti (Acta Universitatis Purkynianae, Philosophica et historica III/1995, Studia Historica II), Ústí nad Labem, 1997; StAnNEK, A., Telemachs Brüder. Die höfischen Bildungsreise des 17. Jahrhunderts, Frankfurt am Mein, 2001; SchudT, L., Italienreisen im 17. und 18. Jahrhundert, Wien - München, 1959; LeIBETSEDER, M., Die Kavaliertours: adelige Erziehungsreisen im 17. und 18. Jahrhundert, Köln, 2004; G. HEIß, "Standes Erziehung und Schulunterricht. Zur Bildung des niederösterreichischen Adeligen in der frühen Neuzeit", en Adel im Wandel, pp. 391-427; Z. HoJdA, "Česká aristokracie a barokní Evropa”, en L. SLAvíčEK (ed.), Artis pictoriae amatores, pp. 63-95.

${ }^{9}$ Algunas cartas de recomendación fueron dirigidas por ejemplo al Marqués de los Balbases o al Marqués de Grana. SOA Trreboň, filial Jindríichův Hradec, Familia Černín, cartón 260, 261, correspondencia de Humprecht Jan Černín de Chudenic, 1681-1682.

${ }^{10}$ Pablo de Spínola Doria, duque de Sanseverino y de Sesto, tercer marqués de los Balbases, marqués de Pontecurone (1628?, 1632?-1699), gobernador de Milán 1668-1670; embajador del Rey de España en la Corte Imperial en Viena 1670, 1676, en París 1677; perteneció al Consejo de Estado y Consejo de la Guerra. 
de Mancera ${ }^{11}$, que durante mi embajada en Venecia, él alli era embajador español. Estos dos señores ahora desempeñan puestos muy relevantes y figuran entre los caballeros más importantes de Madrid" "2. El viaje de Heřman Jakub Černín de Chudenice no sólo representaba el poder económico y social de la familia Černín e indicaba el futuro papel importante que el joven Cernín jugaría en la política de Europa Central, sino que, en cierta forma, rehabilitaba los deseos nunca cumplidos de Černín padre, de visitar el Reino de España, pues él en su juventud no tuvo tanta suerte como su hijo. Hizo su viaje de estudios durante los años inseguros de la guerra de los Treinta Años y su madre, Zuzana Černínová de Chudenice, viuda encargada en la administración de los bienes familiares, apenas tuvo dinero para subvencionar a su hijo su estancia en Italia y Francia entre los años 1644-1646, por lo que su petición de seguir viajando hacia Madrid, fue rechazada ${ }^{13}$.

Heřman Jakub Černín comenzó su viaje saliendo de Praga el día 19 de diciembre de 1678, a la edad de 19 años. Le acompañaron su mayordomo y preceptor Ludolph Bockelkamp, su camarero Hendrich Henisch y el paje Václav Př́ihoda. El itinerario les llevó por Alemania ${ }^{14}$, Italia ${ }^{15}$, Saboya y sur de Francia ${ }^{16}$, España y Portugal. Antes de entrar en las tierras españolas, el día 5 de octubre de 1681, Černín se encontró con otro aristócrata del Reino de Bohemia -el conde Ferdinand Leopold Špork (1664-1711) - a quien conoció durante sus estudios en la Academía Noble de Turín en Italia ${ }^{17}$-y quien era hermano menor de František Antonín Špork $(1662-1738)^{18}$, el importante mecenas de artistas, jansenista y enemigo declarado de los jesuitas. Los condes Černín y Špork, con sus mayordomos Bokhelkamp y Amsterat, hicieron juntos todo el viaje por España.

Černín padre preparó el itinerario del viaje personalmente ${ }^{19}$. Además, enviaba con frecuencia cartas en alemán e italiano a su hijo y a su mayordomo, con instrucciones precisas sobre lo que tenían que visitar en cada parte. Ante todo, las recomendaciones para ver las ciudades de Italia, que el padre conocía personalmente, estaban descritas hasta el último detalle. Y sin embargo, las informaciones que el padre podía proporcionar a su hijo sobre España, eran breves y lejanas, más orientadas a los comentarios de la situación política que al conocimiento del país, obtenidos a través sus relaciones diplomáticas, y escuchando los comentarios de viajes hechos por otros ca-

${ }^{11}$ Antonio Sebastián de Toledo, Molina y Salazar, segundo marqués de Mancera, señor de Mármol y de las Cinco Villas-Virrey de Nueva España, mayordomo mayor de la reina madre Mariana de Austria, desde 1679 presidente del Consejo de Castilla.

${ }^{12}$ La carta estaba escrita en alemán: "Den venedischen Ambasciatod khanst auch visitieren, den Duca de Sesto, Marches de los Balbases so hier am Kayserlichen Hof als ich den Toison bekommen Spanischer Ambasciador gewesen; wie auch dem Marches Mansera so bey meynem Kayserlichen Ambasciata zur Venedig er aldaher spanischer Bottschafter wahr und jetzo beide grosse Chargen haben und zu Madrid hochangenehme Herren sein". SOA Třeboň, filial Jindríichův Hradec, Familia Černín, cartón 261, carta de Humprecht Jan Černín de 22 de agosto de 1681.

${ }^{13}$ Humprecht Jan Černín de Chudenice (Černín padre) empezó su viaje en 1645 junto con otro noble checo, Rudolf Rašín de Rizmburg, con su mayordomo y con dos sirvientes.

${ }^{14}$ Múnich, Salzburgo, Innsbruck.

15 Venecia, Padua, Verona, Mantua, Bologna, Florencia, Siena, Roma, Nápoles, Asís, Perugia, Ancona, Bologna, Mantua, Piacenza, Cremona, Génova.

${ }^{16}$ Lyon, Avignon, Orange, Toulon, Marsella, Arles, Nimes, Montpellier, Narbonne, Perpignan.

17 La lista de estudiantes en la Academía de Turín está en el archivo SOA Třeboň, filial Jindŕichův Hradec, Familia Černín, cartón 262, Noms des Accademistes de Turin.

${ }_{18}$ Preiss, P., František Antonín Špork a barokní kultura v Čechách, Praga-Litomyšl, 2003; Ottưv slovník naučný, Tomo 23, Praga, 1905, pp. 901-903.

${ }^{19}$ El itinerario del viaje escrito por Humprecht Jan Černín se encuentra en el archivo SOA Třeboň, filial Jindřichův Hradec, Familia Černín, cartón 260, Länder Reiß-instruction 1679-1681. Véase "spanische Stadt in der Provinz Catalogna Capital undt allerführnebtse Seehafen undt Guberno Stadt Barcelona /besuchen/. Von Barcelona als dann sichersten und sonst vorträglichten Weg (welche ich nicht weiß vorzuschreiben, aber sicher solchen lumine de lumine zur Barcellona schon Kaufleuthen oder Religiosen erfragen werden können) in Gottes Nahmen vollendts nacher Madrid sich begeben...". 
balleros y los relatos de los comerciantes ${ }^{20}$. Desde su punto de vista, lo más importante que tenía que cumplir el joven Černín durante su estancia en España, era la visita a la Corte de Madrid, a la Corte Virreinal en Barcelona y a los lugares con fama mundial, como por ejemplo los Palacios Reales de El Escorial o de Aranjuez ${ }^{21}$. El resto de los lugares a visitar pudo elegirlos Heřman Jakub Černín libremente, pero con ciertas condiciones: "Y a lo mejor sería bueno, que mi hijo conociera no sólo la Corte Real de Madrid, sino que visitara también otras grandes ciudades, en las que haya algo importante que ver, y que visitara también los lugares curiosos en España"22. Así el joven caballero tuvo en España mucha más independencia y gozó de más libertad respecto a las órdenes de su padre, que en cualquier otro país. Éste sugirió que se quedara en España hasta el mes de mayo del año siguiente, porque en este mes se celebraban las fiestas más importantes como las Fiestas de Toros o Paseos del Prado, sin las cuales su conocimiento de la vida en el Reino de España, nunca estaría completo ${ }^{23}$.

El itinerario del viaje de Černín por España, casi copiaba los lugares que elegían otros viajeros de su época para visitar este país. Esto se debía a la poca densidad de la población y a la escasez de las carreteras en la Península Ibérica en el siglo XVII. Černín con su séquito entró por la frontera cerca de La Jonquera. Siguió su camino hasta Girona, Sant Celoni y Barcelona, donde paró durante diez días. Visitó Montserrat, Lleida y por Fraga, Bujarelos, Zaragoza, Calatayud, Fuencaliente llegó a Alcalá de Henares y Madrid. Después de pasar veinte días conociendo el ambiente de la Corte, partió de allí para conocer el oeste y el sur de la Península. Pasó por Talavera de la Reina, Mérida, Badajoz, cruzó la frontera de Portugal en Elvas y siguió hacia Lisboa. Volvió otra vez por Elvas y Badajoz y pasó por Monasterio a Sevilla, Jerez de la Frontera, Puerto de Santa María, Cádiz, Granada, Alcalá la Real, Córdoba, Ciudad Real y por Orgaz, Toledo y Aranjuez se volvió a Madrid ${ }^{24}$. Allí, el día 5 de abril, hizo la última anotación en su diario ${ }^{25}$. Sus pasos siguientes se pueden reconstruir gracias a la correspondencia conservada en el archivo familiar de Jindřichův Hradec. Así se sabe, que a principios del mes del mayo se trasladó por Vizcaya, Bayona y Burdeos hasta París ${ }^{26}$.

En una instrucción escrita ${ }^{27}$ antes de empezar este viaje, Černín padre ordenó a su hijo que escribiera un diario en el idioma de cada país por el que estuviera viajando. Gracias a querer cumplir este deseo del padre, el joven se convirtió en el autor de un diario especial, que, no sólo

20 Černín padre especifica el origen de sus informaciones en las cartas al hijo. Así sabemos que en España estuvieron también los condes de Ziznendorf, Max von Thun, hermano del obispo de Salzburg, etc. SOA Treboň, filial Jinđ̛richův Hradec, Familia Černín, cartón 261.

21 SOA Třeboň, filial Jind̛́richův Hradec, Familia Černín, cartón 260, Länder Reiß-instruction 1679-1681.

${ }^{22}$ Ibidem. En original alemán: "Undt nachdeme gut wäre, dass Mein Sohn nicht nur Madrid und die Hofstatt alleyn sondern auch etwas von andern considerablen Städten wo was notables zu sehen, curiosen Örthen in Spanien besichtigen thäts, als sollen sie derob sein..."

${ }^{23}$ Además del diario los acontecimientos de Madrid describen también las cartas de Černín padre y de Andreas Gladiche. Véase SOA Třeboň, filial Jinđ̛richův Hradec, Familia Černín, cartón 262.

${ }_{24}$ Černín en España seguía el itinerario de otros viajeros europeos en su época. Véase J. García Mercadal, Viajes de extranjeros por España y Portugal, III, Castilla y León, 1999; A. Anselmi (edición), El diario del viaje a España del cardenal Francesco Barberini (1626), escrito por el célebre erudito, mecenas y coleccionista Cassiano del Pozzo, Aranjuez, 2004; X. A. NeIra Cruz (ed.), El viaje a Compostela de Cosme III de Médicis, Santiago de Compostela, 2004; F. HrubÝ, Lev Vilém z Kounic. Barokni kavalír: Jeho deník z cesty do Itálie a Španělska a osudy Kounické rodiny v letech 1550-1650 (K vydání prripravila L. Urbánková-Hrubá), Brno, 1987.

${ }^{25}$ Durante su estancia en Madrid le llegó la noticia de la muerte de su padre, lo que le obligó a terminar su viaje. Estas circunstancias fueron probablemente también la razón para interrumpir la escritura de su diario, que concluye con la descripción de las solemnidades de la Semana Santa en Madrid en abril de 1682.

26 SOA Třeboň, filial Jinđřichův Hradec, Familia Černín, cartón 261, Ludolph Bokelkamp a Heřman Jakub Černín, carta de 11 de mayo de 1681 .

27 SOA Třeboň, filial Jinđŕichův Hradec, cartón 258, fol. 329-330. 
recorre su camino europeo, sino que también sirve como un interesante documento lingüístico. El diario que escribía de su puño y letra, está escrito en checo, alemán, italiano, francés y español. Además existe una copia en limpio, que fue enviada por partes a Černín padre, junto con las cartas durante todo el viaje. Herman Jakub sabía que el padre iba a leer el diario con gran atención y por eso en la copia dejó aparte algunas notas de su vida privada que aparecían en el escrito original y que en ciertos momentos a su padre no le hubieran gustado ${ }^{28}$.

El espacio más amplio en su diario, lo dedicó el conde Černín a la descripción de los encuentros con las personas importantes, las fiestas y los monumentos históricos. Le emocionó la atmósfera de cada lugar visitado, engrandecida a veces con la celebración de las fiestas lugareñas, acompañadas por el engalanamiento especial de sus calles, costumbre que se diferenciaba de lo que conocía de su país natal. Aparecen descritas en su diario las fiestas profanas, carnestolendas, carnavales, juegos de cañas, fiestas de toros, comedias y las celebraciones litúrgicas, misa del Año Nuevo, procesiones y solemnidades de la Semana Santa, fiestas regionales de santos patrones. El interés por estos acontecimientos y la preferencia en describirlos con más detalle que los tratados políticos no era cuestión de la inexperiencia del joven caballero. Las fiestas en el Barroco formaban parte esencial de la vida y servían para acrecentar las fantasías de la gente en sus paisajes imaginarios, llenos de colores, luces y de trajes de lujo y de bullicio, acompañados de los juegos tradicionales, durante los cuales, los participantes se escondían detrás de un disfraz de alegría, que durante las solemnidades religiosas cambiaban por el arrepentimiento.

Los comentarios sobre la arquitectura y los objetos artísticos contienen en el diario, casi en todos los casos, la descripción básica de cada obra, complementada con las propias observaciones de Černín. No faltan las evaluaciones personales del objeto normalmente reducidas a la simple constatación: maravilloso, hermoso, bonito, lindo, bueno o rico. Aunque se nota que los conocimientos de Černín no carecen de cierta erudición, no es posible ver en este joven a un especialista o experto en arte (aunque en el futuro tendría que jugar el papel de uno de los mecenas de arte más importantes de Europa Central). Se advierte que le llamaban la atención ante todo las obras arquitectónicas, cuya importacia ya estaba públicamente confirmada y que conocía por medio del padre, su preceptor, sus guías ocasionales o los libros de viajes. Algunas veces sus informaciones son inexactas y adulteradas, respecto al origen del objeto o a su historia. Otras veces, mezcla las referencias reales con leyendas curiosas o historias ficticias. Una de estas historias la apuntó en Granada: "Después de comer fuimos al Monte Santo, media legua de Granada, Collegio grande de canónigos, adonde vimos las cuevas en las quales habitauan doce Santos discípulos de San Yago, los quales fueron cremados de los moros en las mismas cuebas y sus santas çeniças se hallaron alli milagrosamente a cabo de muchísimos años, y en unas peñas, que allí estauan se hallaron 30 libros de los Santos, que descriuen los concillos de los Apóstoles. Estos libros dicen estar en Roma para enterpretarlos. Los quales están ya todos enterpretados fuera uno que llaman el Mudo"29. Asimismo, muchas veces, Černín da la misma importancia a las obras maestras

${ }^{28}$ Existen tres versiones de este diario. El autógrafo está guardado en la Biblioteca Nacional de la República Checa en Praga con la signatura XXIII F 30, XXIII F 43. Contiene dos tomos encuadernados en piel marrón. El segundo se encuentra en el archivo SOA Tŕeboň, filial Jindŕichův Hradec, cartón 258, fol. 37-125. Fue escrito en pequeños pliegos de papel cosidos con hilo para poder enviarlos a casa junto con las cartas ya durante el viaje. La última versión del diario carece de la parte española del texto y se conserva en la caja con signatura F VIII alfa 1665-1690 del mismo archivo de Jinđ̛́ichův Hradec. Para los detalles véase BílKovÁ, E.-HusÁKovÁ, J.-TesǍ̌́íKOvÁ, A., op. cit., 2004, pp. 89-118.

${ }^{29}$ Se trataba de una falsificación elaborada por los moriscos nobles a finales del siglo XVI, cuando se discutía su posible expulsión de la ciudad de Granada. Justo en el año 1682 anunció la Iglesia de Roma a los Plúmbeos de herejía. García AREnAL, M., "El entorno de los plomos: historiografía y linaje", Al-Qantara, XXIV, 2, 2003, 295-325. Acerca de Sacro Monte en Granada véase Marías Franco, F., "El verdadero Sacro Monte, de Granada a La Salceda: Don Pedro González de Mendoza, Obispo de Sigüenza, y el Monte Celia", Anuario del Departamento de Historia y Teoría del Arte, N. ${ }^{\circ} 4,1992$, pp. 133-144. 
que a los objetos de poca calidad artística pero con mucha fama religiosa, milagrosa o curiosa. Sus textos a menudo comienzan con notas como me dijeron, se dice, nos enseñaron, para justificar su información sobre lo que escribe.

La calidad de las informaciones que el conde Černín apuntaba en su diario, dependía de la calificación de su guía o de las referencias adquiridas en los libros. Sólo en contadas veces buscó los servicios de un guía profesional. Las informaciones sobre los monumentos históricos, las conseguía casi siempre de los nobles, diplomáticos o de los compatriotas que vivían por allí principalmente, de los eclesiásticos y de los comerciantes. La visita a los monumentos históricos o religiosos formaba parte de los encuentros sociales y tan importante como el monumento en sí, era la presencia del acompañante con el que Černín hacía la visita. Por ejemplo, en Barcelona y Girona, sirvió de guía a los condes Černín y Špork su compatriota, el barón Věžník de Věžník del Reino de Bohemia, que era coronel del ejército alemán ${ }^{30}$. Les enseñó el puerto y la marina, las galeras nuevas, los edificios más importantes de la ciudad y junto con otros nobles salieron al paseo y al teatro y visitaron una ermita fuera de la ciudad. El Palacio Virreinal le fue mostrado por el Virrey en persona, marqués de Bornounville, quien les invitó a comer y a jugar a las cartas. Acompañado por el Cónsul de Holanda visitó Černín otro palacio con hermosos jardines. Cada ruta por la ciudad, cada invitación para comer o participar en algún juego, visita a teatro o a algún palacio, a jardines, a las galerías artísticas o tesoros eclesiásticos, se convertían en un encuentro de etiqueta y daban cuenta de la cortesía y la diplomacia personal ${ }^{31}$.

Las obras artísticas en el diario de Černín no están descritas de manera exhaustiva. El viajero apuntaba en cada sitio los edificios y objetos que más le emocionaban y olvidaba mencionar otros, que podían tener más importancia histórica o artística. Algunas veces no se conformaba sólo con las informaciones adquiridas por sus guías. Comparando el texto del diario, con el índice de diarios de viajes y de los "bedecker" publicados en su época, se ve que, de vez en cuando, copiaba algunos textos de estos libros. Por ejemplo, el texto del diario del holandés Antonio Brunel, redactado en 1654 y publicado en 1666, le inspiró para describir la belleza del Palacio Real de Aranjuez: "En esta villa de Aranjuez, el Rey vive con toda su Corte, un mes de la primavera. No [h] ay duda ninguna, que es un puesto de mucho divertimiento. Los Españoles que no han visto jamás otro semejante, lo comparan a los Campos Eliseos y los poetas, citan en sus comedias el jardín y las flores como si allí viviese la Dea Flora. Consiste este puesto delicioso en una vastísima llanura de muchas leguas, que está bañada por el medio del Río Tajo, que tiene a ambas partes muchos bosques, en los quales [h] ay lindas cazas y alli no puede nadie, bajo gran pena caçar, ni tirar un golpe. Alrededor de la villa y del Real Palaçio, en çerca una legua, están por todo en gran quantidad viales muy largos y anchos de olmos altísimos. El jardín está junto al Palazio en una isla del río muy agradable, más larga que ancha y cruzada de muchas calles cubiertas con árboles fruteros debajo los quales lindamente se puede pasear, quando haze calor. Mas pecado es que están tan estrechas y baxas. Tiene también muchas bonitas fuentes mas no son suficientes para un Real Jardín. En somma de este sitio, que es de su natura agredable, si el arte quería cobrar que en los Españoles falta, se pudiera allá haser un paraíso terrestre"32.

30 Sobre la familia Věžníkové de Věžník Ottův slovník naučný, Tomo 26, Praga, 1907, pp. 637-639.

31 En Madrid pasó Černín mucho tiempo en compañía del Embajador Imperial en la Corte Real española marqués Otto Heinrich Carreto, marqués de Grana, conde de Millesimo, con otros nobles centroeuropeos, con el nuncio del Papa o con los embajadores de Francia y de Holanda.

${ }^{32}$ Compara el texto siguiente con el diario que redactó en 1654 Antonio de Brunel, señor de San Mauricio, quien realizó servicios diplomáticos para Holanda y también fue mentor de unos nobles jóvenes holandeses durante sus viajes por España. Más tarde lo convirtió en su diario del viaje español, impreso en Paris, Colonia, Bruselas y La Haya en 1666. Es casi seguro que Černín tuvo este libro en sus manos y lo utilizó para sacar informaciones y formar sus propias opiniones sobre los sitios visitados en España. Véase la descripción de Aranjuez de Brunel: "El 5 de mayo fuimos a Aranjuez para ver alli a la Corte y esa agradable residencia donde el rey pasa todos los años un mes de primavera. Es 
Todo el viaje español está marcado por el interés especial de Černín por la arquitectura. Al principio de su viaje europeo, el joven contrató en Roma a un maestro de arquitectura para que le enseñara las reglas de la construcción. Después apuntaba con frecuencia en su diario las informaciones sobre la disposición urbanística de las ciudades, sobre los edificios concretos, sobre los materiales para la edificación, sobre la ornamentación, el origen del edificio, sobre los gastos de la construcción. Llegando a cada ciudad, Černín se manejaba siempre de la misma manera. Si le era posible, primero subía a la torre para poder ver la forma de la ciudad y su colocación en el terreno y se fijaba en su situación, si estaba colocada en la orilla del río, en las montañas o en la llanura. Por ejemplo subiendo la torre más alta de Zaragoza apuntó que la ciudad tenía forma casi circular, que estaba colocada en plena llanura y que por su centro pasaba el río Ebro. Sobre la situación de Lisboa escribió, que estaba situado en siete colinas a lo largo del río Tajo. Le emocionó la arquitectura excepcional de la Giralda de Sevilla, y sobre todo le sorprendió que era posible subirla montando a caballo: "Subimos también la torre, que llaman Giralda por ser la más alta de España. Su altura es 387 pasos y se puede subir a caballo, porque no tiene escaleras. Desde arriba vimos la situación de la ciudad, que está puesta largo al río Guadalquivir en forma oval y tiene alrededor muchos arravallos. El más grande es al otra parte del río que se llama Triana,"33.

Su interés práctico se concentró en la arquitectura de fortificación y en cómo proteger las ciudades durante la guerra. Con frecuencia visitaba las fortalezas, por ejemplo en Bellegarde, en Badajoz o en la ciudad portuguesa de Elvas, sobre la que se apuntó que es muy bién fortificada y tiene una citadela de cuatro bastiones. No le molestó esperar para obtener permiso para visitar la fortaleza real en Lisboa. Černín describía detalladamente la estructura de cada sistema de fortificación, su disposición en terreno, las murallas exteriores e interiores, el número de los soldados presentes, la cantidad de la munición. Asimismo se entusiasmó mucho por el sistema de la fortificación de Cádiz: "Después de haber tomado un bocado, fuimos a ver la ciudad alrededor y vimos en el puerto más de 50 nauios françeses mercailes, que viniron da Levante para ir a las rayas de Françia. La ciudad no sólo es fuerte de natura porque está fabricada la más parte en peñas que empedissen el desbarco, mas en los lugares, adonde no los hay, hay buenas fortificaciones. El Puerto es muy vasto y sicuro, pero los vientos de Levante hasen muchio daño a las fortificaciones porque cobren los bastiones de arena, como la más parte de ellos están cubiertos una legua en tierra firma. De la parte de Levante vimos dos altas y viejas torres que disen ser las Columnas Herculeas"34. La afición de Černín a la arquitectura útil se repite en sus descripciones de los edificios públicos, como puentes, molinos, acueductos, hospitales, caballerizas, incluso en los detalles técnicos.

Otra afición del joven conde Černín eran los edificios, que ya en su tiempo se veían como los monumentos históricos. Describía con interés la arquitectura clásica. En su época, el mundo antiguo ya estaba aceptado por la sociedad, reconciliado con el mundo dominado por el Dios cristiano y el eco de la cultura clásica respondía por todas partes al pensamiento de cada persona culta. No sorprende pues la amplitud que Černín dedicó a la ciudad de Mérida: "Mérida es una antigua ciudad, que hizo fabricar el Emperador Titto Vespasiano. Nos dijeron que esta ciudad contenía en su circonferençia 60 millas de Italia y tenía 60 puertas y había 6000 hombres de

\footnotetext{
sin duda un lugar agradable, y los españoles que no han visto otros semejantes, lo comparan con los Campos Elíseos. Los poetas, en sus comedias, citan sus jardines y sus flores como de un sitio donde reina Flora, acompañada de todos sus tesoros. Su situación es bellísima y sus avenidas muy agradables. Antes de aproximarse alli se pasa el Tajo por un puente de madera que tiene una puerta en el extremo para cerrarlo cuando la Corte no está allí... Más allá del puente toman a mano derecho y en un rincón, que hace el Tajo, se ven los altos olmos y las plantaciones que rodean la casa del Rey. Lo primero que se encuentran en un parque cerrado con tapias bastante bastas y divididas por algunos paseos. Caballero Pérez, M.-Góngora Ayala, P., "Viajeros por el Sur de Madrid, Siglos XV al XIX”, I. parte, Anales del Instituto de Estudios Históricos del Sur de Madrid "Jiménez de Gregorio", No. 6, 2006, pp. 51-70.

33 SOA Třeboň, filial Jindřichův Hradec, cartón 258.

34 Ibidem.
} 
guarniçión. En lo presente pareçe más una billa que ciudad. Se veen pero aún muchas ruinas de las antiguas fábricas, como el Arco Triumphale del Tito Vespasiano Emperador, su Palaçio y alrededor de la ciudad muchos antiguos condotos de aguas. De la parte de donde se va a Badajos es una puente muy linda, larga 85 passos fabricada de los Romanos"35.

Igual que por los monumentos de la Antigüedad se interesó por los edificios tanto profanos como sacros, góticos y renacentistas, tanto por los palacios de los reyes cristianos como por los de los moros. Notó el carácter único de las obras hechas en estilo árabe y mudéjar, que nunca había conocido. Lo que le llamó más poderosamente su atención fue Granada con su "Lambra". Allí, distinguía correctamente entre los edificios árabes y el palacio, que mandó construir el emperador Carlos V: "Después de comer fuimos a ver la Lambra fabricada de Moros encima de un monte para habitatión de los Reyes, en la qual se veen muchas salas al uso antiguo muy hermosas, muchos baños todos de mármoles y un profumador también de mármol puesto en el suelo de una sala adonde las Reinas moras se profumavan. Tiene también una sala de secretos en la qual pueden hablar dos personas, uno con el otro, sin que oiga nada el que está en el medio dellos. Los patios son çircondados de muchísimas chicas columnas de mármol densamente bien adornados. Junto deste Palaçio hay un otro que Carlos V Emperador hizo fabricar por su habitazión del aquel. Es en quadro y tiene lindísimas fachiadas en todos cuatro lados. El patio de dentro es redondo de gordas columnas. Subimos también una torre para ver la çituazión de la ciudad que es de buena grandeça, puesta en medio de tres montes que la guandan"36.

Con idéntica afición se dedicó a describir la arquitectura moderna en su tiempo. Así expresa la impresión que le causó la visita de recién terminado Hospital de la Caridad en Sevilla: "fábrica тиy superba, que fue hecha nueva de elemosinas, que dio la noblesa de Seuilla. Mantiene siempre muchíssimos enfermos que tienen males incurables y tiene una hermosísima iglesia llena de pinturas de grandíssimo preçio y arte" "37. Lo que no apuntó fue los nombres de los pintores -Murillo, Juan de Valdés Leal ${ }^{38}$ - Con la misma afición habló sobre la recién reconstruida iglesia de Nuesta Señora la Blanca en Sevilla por Pedro Sánchez Falconete, utilizando la yesería en la nave principal y en la bóveda y sobre muchos más ${ }^{39}$.

Aunque sabía bien apreciar la calidad de pinturas y de esculturas ${ }^{40}$, las obras concretas y los nombres de sus autores, los apuntó en el diario sólo esporádicamente. Las esculturas sólo las nombró dos veces. Durante una visita de la Casa del Campo llamó su atención la estatua de Felipe III a caballo, obra virtuosa hecha de bronce, trabajo del italiano Giovanni da Bologna, terminado en 1616 por su discípulo Pietro Tacca ${ }^{41}$. En el monasterio de San Jerónimo en Sevilla fue "adonde bimos la tanto rinomada estatua de S[an] Gerónomo hecha de barro de la qual rara y artificiosa hechura hablan muchos libros históricos". Se trata de la escultura de San Jerónimo hecha en barro cocido y policromado por el italiano Pietro Torrigiano en el año 1525 (fig. 3$)^{42}$.

35 Ibidem.

36 Ibidem.

37 Ibidem.

38 Véase Valdivieso, E.-Serrera, J. M., El Hospital de la Caridad de Sevilla, Sevilla-Valladolid, 1979.

39 El origen de esta iglesia fue una de las principales sinagogas del siglo XIII, transformada en la iglesia cristiana en el siglo XIV. Pedro Sánchez Falconete la había reconstruido a estilo barroco a finales del siglo XVII con la yesería en el techo y en la nave principal, obra de los hermanos Pedro y Miguel Borja sobre trazado de Pedro Roldán. BERNALES Ballesteros, J., Pedro Roldán: maestro de escultura, 1624-1699, Sevilla, 1973.

40 Véase BinkovÁ, S.-PoliŠEnSKÝ, J.: op. cit., 1989, pp. 393.

41 Lewy, E., Pietro Tacca: Ein Beitrag zur Geschichte Florentiner Skulptur, Köln, 1900.

42 Pedro Torrigiano (Florencia 1472-Sevilla 1528) fue compañero y rival de Miguel Ángel en el famoso "Jardín de los Médicis" en Florencia. En 1522 llegó a Sevilla e hizo dos trabajos importantes para el Monasterio de San Jerónimo, la estatua del patrón de la iglesia, de San Jerónimo y de la Virgen de Belén. La estatua de San Jerónimo realizada a tamaño natural, fue elaborada en barro cocido, técnica muy utilizada en Italia y desde el siglo XV enlazada con la tradición de la escultura sevillana. Hernández Perera, J.: Escultores florentinos en España. Madrid, 1957. 


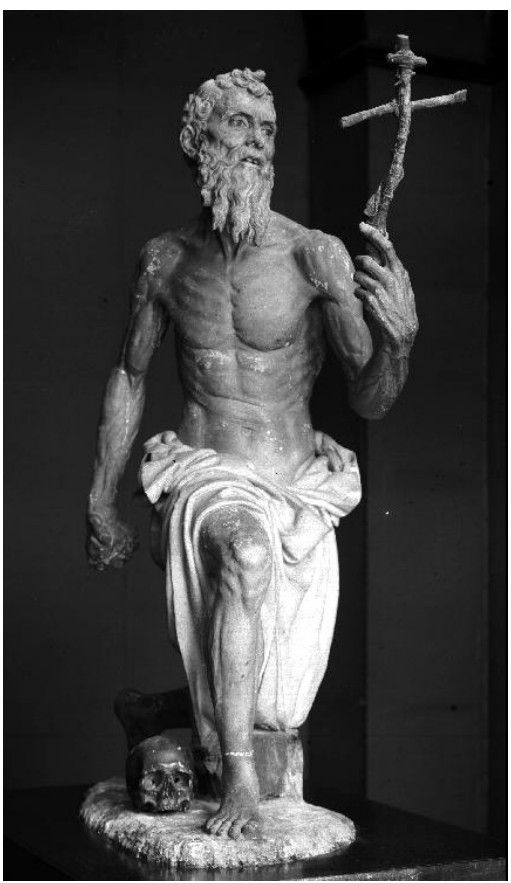

Fig. 3. Pietro Torrigiano, Estatua de San Jerónimo, Sevilla, Museo de Bellas Artes.

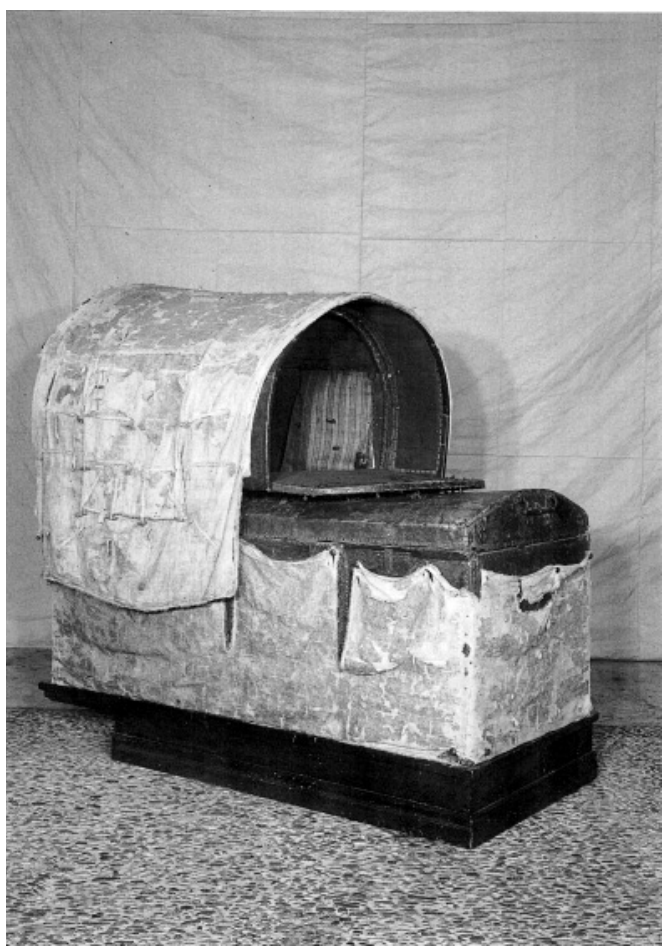

Fig. 4. Camilla del Emperador Carlos V, ${ }^{\circ}$ Patrimonio Nacional Madrid.

Černín no tenía profundos conocimientos de botánica y por eso no sorprende que durante las visitas de los jardines de los palacios reales y nobles, se interesaba ante todo por las flores y los árboles exóticos para un centroeuropeo, como en el jardín del palacio de los duques de Medinaceli en Bornos, que estaba lleno de naranjos, naranjos de China y otros frutales. Su interés por las curiosidades técnicas aumentaba observando las fuentes, surtidores y juegos de agua. Sobre el jardín del palacio del cónsul de Holanda en Barcelona escribió, que "es muy hermoso y abundante de aguas artificiales", así como el jardín del marqués de Fontiera en Lisboa, que tenía abundancia de juegos de agua y el Alcázar Real en Sevilla "junto al qual está un hermoso jardín lleno de naranjas y otros raros fruttos y fuentes de burlas muy diferentes unos de otros".

Durante las visitas a los palacios los dueños le enseñaban con orgullo los espacios de representación de sus residencias y así pudo Černín apreciar su abigarramiento, el lujo de su mobiliario, las galerías y los gabinetes de curiosidades. El Palacio del Almirante de Castilla ${ }^{43}$ en Madrid le parecía "muy lindamente adereçado con espejos y otras galanterías y tiene muchíssimas pinturas de manos de mas balientes hombres que hay hauido al mundo" 44 . Con alegría aceptó también la posibilidad de visitar la armería del Palacio Real en Madrid, llena de las armas y armaduras de los reyes y príncipes de España. Entre los miles de objetos llamó su atención "un grande caxón del quale Carlos Quinto Emperador se sirvió en campaña por cama, mesa y aposiento” (fig. 4$)^{45}$.

43 Juan Gaspar Enríquez de Cabrera (1625-1691), 9. Almirante de Castilia, 6. duque de Medina de Rioseco.

44 SOA Třeboň, filial Jind̛́richův Hradec, cartón 258.

45 Véase De Valencia, Don Juan, Catálogo histórico-descriptivo de la Real Armería de Madrid, Madrid, 1898, pp. 390-391. La imagen fue concedida por Patrimonio Nacional Madrid, Palacio Real. 
El período barroco es famoso también por la profunda fe de la gente y por su excitante creencia en las poderes de los santos y en sus milagros. Así las santas imágenes y las reliquias no se contemplaban tanto como objetos del arte sino como objetos sagrados. Černín no perdió ninguna posibilidad de visitar las iglesias durante su camino, para oír misas, admirar su construcción, rezar ante las santas imágenes y admirar los tesoros de los santos lugares. Constantemente nombraba los famosos santos, más los milagros por los que eran conocidos los santos y sus historias. Si tenía la posibilidad, volvía al mismo templo para orar junto a las imágenes más importantes. Visitó la estatua de Nuestra Señora con las benedictas manos en el monasterio de Montserrat, admiró la imagen de Nuestra Señora del Pilar en Zaragoza que es una imagen muy milagrosa. Se fijó en el sepulcro de San Pedro de Zaragoza, en Lisboa visitó el sepulcro de San Antonio de Padua. Se dejó enseñar los tesoros de las iglesias y de los monasterios con los relicarios y otros objetos de valor. En el monasterio de los benedictinos de Montserrat le enseñaron objetos de oro y de plata, entre los que destacó los cabellos de la Virgen María. En Lisboa, después de oír misa en la iglesia Nossa Senhora de Graça, vio también su tesoro: "vimos una muy grande cruz de oro bien labrada y empedrada de diamantes y otras piedras muy preçiosas embiada por regalo a esta Iglesia de un Obispo de las Indias. Vimos también un Sagrario todo de cristal de Rocca de una hechura muy preçiosa, que fue presente de un Vyrrey de las Indias" "46. En la iglesia de canónigos en Monte Sacro en Granada había "en la Sacristía tres paçes de gran valor, la una dellas tiene una gran perla de singular grandeça en forma de una bóueda, cosa prodigiosa" 47 .

El diario no contiene ninguna información sobre compras de obras artísticas ni de libros, se notifican sólo las compras de trajes nuevos hechos a la española y de los accesorios ${ }^{48}$. A pesar de que ya en la mitad del siglo XVII, en Europa predominaba la moda del barroco francés, la Casa Real española prefería los trajes tradicionales, reminiscencia de la época de oro de la nobleza renacentista española. Justamente después de llegar a Madrid, el conde Černín se vio obligado a hacerse los trajes a la española para él y para su séquito. En el diario, no olvidó quejarse de que, después de haber vestido por primera vez el traje cosido a la manera española, no se pudo mover bien durante todo el día, porque le estaba prieto y sus zapatos mucho más ${ }^{49}$. Las cuentas del viaje, no se han conservado por lo que no se conoce si Černín adquirió algunos objetos de arte en España.

Cuando volvió a su patria, Černín desempeñó papeles de gran importancia en la vida política del Reino de Bohemia durante la Monarquía de los Habsburgo. Entre los años 1695-1698, fue

46 Se trata de una caja hecha de cristal de Venecia en los años 1608-1609, regalo del arzobispo y gobernador de Goa, Aleixo de Menedez al Convento da Graça en Lisboa y enviado allí junto con la cruz hecha de oro, plata y piedras preciosas. Ambos objetos están ahora guardados en el Museu de Arte Antigua en Lisboa. En el mismo museo hay otra caja hecha de filigrana de oro, que entregó al mismo monasterio Filipa de Vilha, viuda de Matias de Alburquerque, entre los años 1591-1597 virrey de India. N. Vassalo E Silva, A herança de Rauluchantim Exposiçao Museu de Sao Roque, Lisboa, 1996, pp. 165-169.

${ }^{47}$ No me ha sido posible identificar estos objetos ni en el libro M. CAPEL MARGARITO, Orfebrería religiosa en Granada, Granada, 1987; CAPel Margarito, M., Iglesias y conventos de Granada: Catálogo de Platería, Cuadernos de arte de la Universidad de Granada, N. ${ }^{\circ}$ 30, 1999, pp. 327-347.

48 "A $18 f$ de [diciem]bre oímos missa en el Colej[i]o Emperial y el resto del día nos ocupamos en mercar lo neçeçario para vestirnos a la española”. SOA Třeboň, filial Jindřichův Hradec, cartón 258.

49 HaJnÁ, M., op. cit., 2002, pp. 84-98. Para comparar véase el texto del diario del francés Antonio de Brunel (1665): "Para hablar al rey es una necesidad el ir vestido de negro. Hasta tal punto que a un enviado del príncipe de Condé le dieron tiempo para vestirse de ese color antes de que le introdujesen ante su majestad, habiéndosele hecho saber que de otro modo no podría tener audiencia." Sobre los zapatos que estaban de moda en la Corte Real en Madrid escribió en mismo Brunel: "Sus zapatos son de forme de pie, y para los elegantes son muy estrechos de suela y de empeine; un pie pequeño y una gruesa pantorrilla son tan estimados, que los galanes se sujetan el pie con cinta para hacerlo parecer pequeño y sufren por ello un gran martirio, al mismo modo que con algún relleno falso de la pierna fingen por entero el parecer ir a la moda...” J. García Mercadal, Viajes de extranjeros, pp. 278. 
Embajador Imperial en Varsovia, de 1689 a 1700 desempeñó el cargo de Mayordomo Mayor del Emperador Leopoldo I y en 1700 fue nombrado Burgrave Mayor del Reino de Bohemia, cargo equivalente al Virrey de este Reino, que era la función más notable que podía conseguir un noble en aquella época. Heredó también de su padre la afición por coleccionar obras de arte, por las construcciones arquitectónicas y por las actividades culturales. Unió la colección de las pinturas de la familia Černín con las de la familia Slavata, que formaban parte de la dote de su primera esposa, condesa María Josefa de Slavata $(1667-1708)^{50}$. Todos sus cuadros, estaban expuestos en la pinacoteca nueva del Palacio de los Černín en Praga, de cuya construcción se encargó después de la muerte de su padre y que por su monumentalidad, preciosidad y por varias formas arquitectónicas evoca el estilo monumental de la arquitectura barroca española ${ }^{51}$. Este palacio aún hoy día se considera la parte más importante de la herencia cultural de los Černín en la República Checa (fig. 5$)^{52}$.

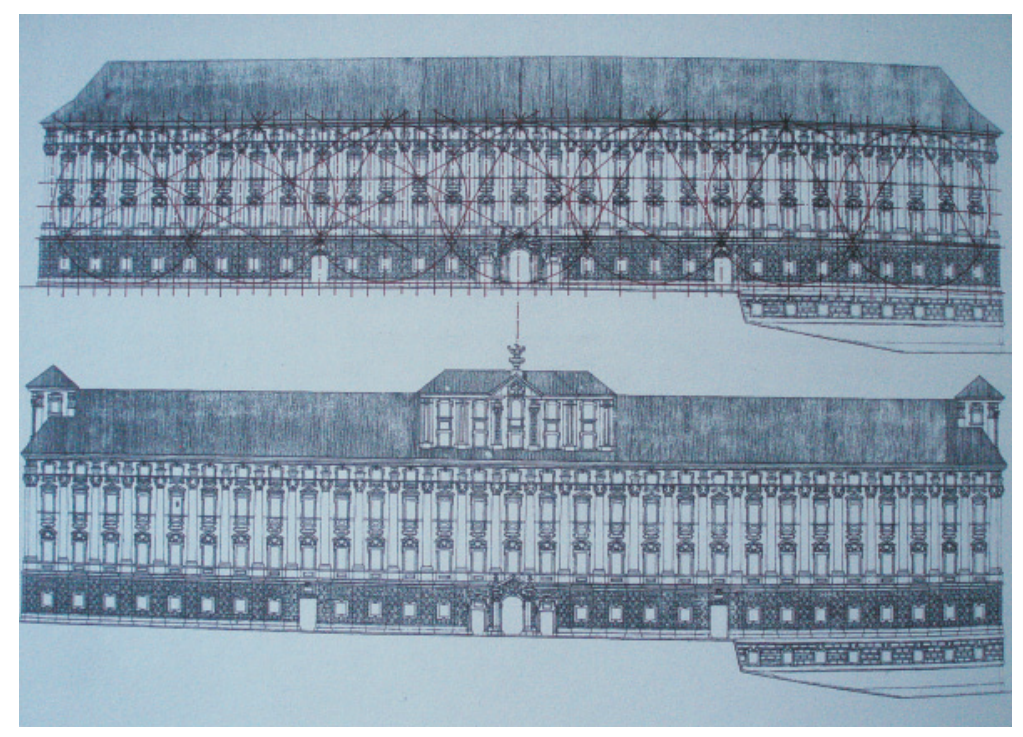

Fig. 5. Planos del Palacio de los Černín en Praga-Hradčany de Francesco Caratti.

Fecha de recepción: 4-VI-2007

Fecha de aceptación: 24-IX-2007

${ }^{50}$ Después de la muerte del Černín padre en 1682, los compromisos sociales y familiares le obligaron a Heřman Jakub a interrumpir su viaje y volverse a casa para ocuparse de sus bienes hereditarios y participar en la división de la herencia entre él, su hermano y su madre. Černín empezó a administrar los bienes de gigantesca amplitud en el Reino de Bohemia, incluido Petrohrad, Kysibel, Vinoř, Landštejn, Kost, Humprecht, Kostomlaty, el Palacio de los Černín en Praga-Hradčany, con los cuales unió la dote de su primera esposa Josefina Slavata de Chlum y Košumberk con el extenso dominio de Jindrírichova Hradce.

${ }^{51}$ La historia detallada de la construcción de este palacio, incluso las fases, los nombres de los arquitectos y la descripción artística se ven descritos en el libro, que contiene también las copias de los planos del palacio sacados de los archivos. LoREnc, V.-TřísKa, K., Černínský palác v Praze, Praha, 1980.

${ }^{52}$ Los planos del Palacio de los Černín en Praga-Hradčany de Francesco Caratti. Publicado en LoRENC, V.-TřísKA, K., op. cit., 1980, pp. 80. 